\title{
TEMPERATURA E TIPO DE PREPARO NA CONSERVAÇÃO DE PRODUTO MINIMAMENTE PROCESSADO DE ABACAXI-'PÉROLA'1
}

\author{
BIANCA SARZI², JOSÉ FERNANDO DURIGAN ${ }^{3}$ OSWALDO DURIVAL ROSSI JÚNIOR ${ }^{4}$
}

\begin{abstract}
RESUMO - O presente trabalho teve como objetivo avaliar o efeito do tipo de preparo ("rodelas" e "metades") e da temperatura de armazenamento $\left(3^{\circ} \mathrm{C}, 6^{\circ} \mathrm{C}\right.$ e $\left.9^{\circ} \mathrm{C}\right)$ na conservação de produto minimamente processado de abacaxi-'Pérola'. Os frutos, depois de selecionados, lavados e desinfectados com cloro, foram armazenados por 12 horas a $10^{\circ} \mathrm{C}$, antes de serem processados sob condições higiênicas, embalados em contentores de polietileno tereftalatado ("rodelas") ou bandeja de isopor recoberta com filme de cloreto de polivinila esticável ("metades") e armazenados por até 12 dias. Os produtos foram avaliados quanto à evolução da atmosfera interna na embalagem, respiração, quantidade de suco drenado e evolução da massa fresca e da aparência. Foram testadas, durante o período de armazenamento, a aceitabilidade pelos consumidores, no início do experimento e enquanto a aparência e a análise microbiológica permitiram. A presença de bactérias mesofílicas e coliformes totais e fecais foi avaliada a cada três dias. Durante o armazenamento, a porcentagem de $\mathrm{O}_{2}$ nas embalagens apresentou decréscimo, enquanto a de $\mathrm{CO}_{2}$ aumentou até $20 \%$ para as "metades" e até $1,86 \%$ para as "rodelas". A intensidade dos cortes no preparo teve influência direta na respiração, assim como nas perdas de suco e de massa fresca. A temperatura influenciou na respiração e foi fator limitante à vida de prateleira do produto, pois os produtos armazenados a $9^{\circ} \mathrm{C}$, conservaram-se por 6 dias, enquanto os mantidos a $3^{\circ} \mathrm{C}$ e $6^{\circ} \mathrm{C}$, por até 9 dias.
\end{abstract}

Termos para indexação: Ananas comosus, armazenamento, respiração, vida de prateleira

\section{TEMPERATURE AND METHOD OF PREPARATION IN PRESERVATION OF THE MINIMALLY PROCESSED PRODUCT OF PÉROLA PINEAPPLES}

\begin{abstract}
The aim of the present study was to determine the effects of two types of preparation ("roundels" and "halves") and of different storages temperatures $\left(3^{\circ} \mathrm{C}, 6^{\circ} \mathrm{C}\right.$ and $\left.9^{\circ} \mathrm{C}\right)$ on the preservation of the minimally processed product of 'Pérola' pineapples. The fruits, after being selected, washed and disinfected with chlorine, were stored for $12 \mathrm{~h}$ at $10^{\circ} \mathrm{C}$, before being processed under hygienic conditions, packaged in polyethylene terephthalate trays ("roundels") or in styrofoam trays covered with a stretchable polyvinyl chloride film ("halves"), and stored for up to 12 days. The products were evaluated regarding the evolution of the internal atmosphere in the packaging, respiration, quantity of juice drained, and the development of fresh mass and appearance. During the storage period, tests were made for consumer acceptability, at the start of the study and while appearance and microbiological analysis allowed. The presence of mesophilic bacteria and fecal and total coliform bacteria was determined every three days. During storage, the percentage of $\mathrm{O}_{2}$ in the packages showed a decrease, while that of $\mathrm{CO}_{2}$ increased up to $20 \%$ for the "halves" and up to $1.86 \%$ for the "roundels." The extent of the cuts in the preparation had a direct influence on respiration, as with the losses of juice and fresh mass. The temperature influenced the respiration and was a limiting factor in the product's shelf life, since the products stored at $9^{\circ} \mathrm{C}$ were preserved for 6 days, while those kept at $3^{\circ} \mathrm{C}$ and $6^{\circ} \mathrm{C}$, for up to 9 days.
\end{abstract}

Index terms: Ananas comosus, storage, respiration, shelf life.

\section{INTRODUÇÃO}

O Brasil produziu cerca de 2,8 milhões de toneladas de abacaxi no ano de 2000 , exportando aproximadamente 15 mil toneladas para Argentina, Uruguai e Portugal. Esta produção coloca-o em posição de destaque, sendo o segundo maior produtor mundial. As principais regiões produtoras são a Sudeste e Nordeste, sendo que o volume comercializado na CEAGESP, no ano de 1999, chegou a 38 mil toneladas, mostrando a grande importância desta fruta no Estado de São Paulo (Agrianual, 2001). As cultivares mais plantadas no Brasil são a 'Pérola' e a 'Smooth Cayenne', sendo a 'Pérola' considerada insuperável para o consumo ao natural, graças a sua polpa suculenta e saborosa (Gonçalves \& Carvalho, 2000).

O abacaxi, apesar de sua grande aceitação e valor nutricional, não prima pela conveniência, o que vai de encontro ao interesse do consumidor, que tem se tornado cada vez mais exigente na aquisição de produtos alimentares, com preferência

1 (Trabalho 172/2001). Recebido: 29/10/2001. Aceito para publicação: 04/06/2002. Parte da Dissertação de Mestrado do primeiro autor. Financiado pela FAPESP processo $\mathrm{n}^{\circ} 12365-4$.

2 Eng ${ }^{\mathrm{a}}$ Agr $^{\mathrm{a}}$ Aluna de Doutorado do Departamento de Tecnologia da FCAV/UNESP, Jaboticabal. Via de acesso Prof. Paulo Donato Castellane, s/n, 14.884-900 Jaboticabal, SP - Telefone: (16) 3209-2675 - biasarzi@fcav.unesp.br

3 Prof. Titular do Departamento de Tecnologia da FCAV/UNESP Jaboticabal. Via de acesso Prof. Paulo Donato Castellane, s/n, 14.884-900 Jaboticabal, SP - Telefone: (16) 3209-2675 - jfduri@fcav.unesp.br

4 Prof. Adjunto do Departamento de Med. Vet. Preventiva e Reprodução Animal da FCAV/UNESP Jaboticabal. Via de acesso Prof. Paulo Donato Castellane, s/n, 14.884-900 Jaboticabal, SP Telefone: 3209-2646 - rossijr@ffcav.unesp.br

Rev. Bras. Frutic., Jaboticabal - SP, v. 24, n. 2, p. 376-380, agosto 2002 
declarada por produtos com grande conveniência, alto valor nutritivo e excelente qualidade sensorial. Isto tem feito com que os produtos minimamente processados ganhem cada vez mais importância no mercado de frutas e oleráceas.

Segundo Cantwell (1992) e Wiley (1994), o produto minimamente processado é aquele fresco, tornado conveniente, com qualidade e garantia de sanidade. Estes produtos, além de facilitar a vida do consumidor, garantem agregação de valor ao produto, permitindo melhores condições de remuneração (Durigan, 2000).

Produtos hortícolas minimamente processados, devido às lesões sofridas durante o preparo, como descasque e cortes, sempre apresentam metabolismo mais acelerado e maior relação superfície/volume do que quando inteiros, o que facilita a perda de água por seus tecidos (Tatsumi et al., 1991).

Chitarra \& Chitarra (1990) recomendam as temperaturas mais baixas para o armazenamento de vegetais, pois retardam o metabolismo, diminuindo a taxa respiratória e a atividade enzimática, evitando ou minimizando alterações no aroma, sabor, textura, cor e demais atributos de qualidade.

$\mathrm{O}$ uso de embalagens, geralmente plásticas, modifica a atmosfera de conservação do produto vegetal, dada a ação da respiração no seu interior, com aumento na concentração de $\mathrm{CO}_{2}$ e diminuição na de $\mathrm{O}_{2}$ (Wiley, 1994). Tais alterações podem diminuir o desenvolvimento microbiano, assim como o desenvolvimento de desordens fisiológicas e de deteriorações bioquímicas.

Elevadas perdas pós-colheita e consumo per capita relativamente baixo podem ser, em parte, atribuídos à falta de conveniência do abacaxi para o consumo ao natural, pois ele exige descasque trabalhoso, apresenta escorrimento de líquido e necessita de contenção em vasilhame adequado e equipamento próprio para este consumo. Procurando tornar o produto mais conveniente, assim como agregar valor ao mesmo, Carbonari et al. (2000) estudaram a influência do preparo e da embalagem na conservação do abacaxi-'Smooth Cayenne' minimamente processado e encontraram vida útil de 11 dias para produtos embalados em polietileno tereflatado (PET), que foi superior àquela dos embalados em cloreto de polivinila (PVC). Prado et al. (2000) avaliaram a influência da desinfecção com hipoclorito de sódio na qualidade do produto minimamente processado de abacaxi'Pérola' e concluíram que este sanitizante tem grande importância na conservação dos produtos, sem influenciar na sua qualidade. Este trabalho teve como objetivo avaliar o efeito do tipo de preparo e da temperatura de armazenamento, na conservação de produto minimamente processado de abacaxi-'Pérola'.

\section{MATERIAL E MÉTODOS}

Utilizaram-se frutos de abacaxi-'Pérola' produzidos em Frutal - MG, colhidos no ponto de maturação "pintado" (Classificação, 2000) e transportados 24 horas após a colheita para o Laboratório de Tecnologia dos Produtos Agrícolas da FCAV Jaboticabal - UNESP, onde foram novamente selecionados, procurando tornar o lote mais uniforme quanto ao grau de maturação e ausência de danos mecânicos ou podridões. Em seguida, as coroas foram retiradas e os frutos lavados com detergente neutro, que tinha como ingrediente ativo o alquilbenzeno sulfonato de sódio, e água corrente, e imersos, por 5 minutos, em água fria $\left(5^{\circ} \mathrm{C}\right)$, contendo $200 \mathrm{mg}$ de cloro. $\mathrm{L}^{-1}$, para desinfecção e retirada de parte do calor de campo. Estes frutos foram mantidos em câmara fria $\left(10^{\circ} \mathrm{C}\right)$, previamente lavada e higienizada com solução de cloro a $200 \mathrm{mg}$. $\mathrm{L}^{-1}$, pelo período de 12 horas.

O processamento foi feito manualmente, a $10^{\circ} \mathrm{C}$, com os utensílios (facas, baldes, escorredores, etc.) previamente higienizados, com solução de cloro a $200 \mathrm{mg} . \mathrm{L}^{-1}$. Os operadores usaram luvas, aventais, gorros e máscaras, procurando proteger ao máximo o produto de prováveis contaminações.

Os frutos foram descascados, cortados em "rodelas" $(1,5$ cm de espessura) ou em "metades" longitudinais, que foram enxaguadas com água sanitizada ( $20 \mathrm{mg}$ de cloro. $\left.\mathrm{L}^{-1}\right)$ e escorridas por 2-3 minutos, e a seguir embaladas e armazenadas sob condições refrigeradas.

Utilizou-se para embalar o produto em "rodelas" a embalagem Neoform ${ }^{\circledR} \mathrm{n}^{\circ} 14$ de polietileno tereftalatado (PET), sem fechamento hermético, com as seguintes medidas: $16,00 \mathrm{~cm} \mathrm{x}$ $17,00 \mathrm{~cm} \times 9,00 \mathrm{~cm}$, e volume de 2,45 litros. Bandeja de isopor com $0,50 \mathrm{~cm}$ de espessura e as dimensões $11,50 \mathrm{~cm} \times 19,00 \mathrm{~cm} \times 4,00 \mathrm{~cm}$, recoberta com filme de cloreto de polivinila (PVC) esticável e espessura de $0,017 \mathrm{~mm}$, perfazendo um volume total de $0,87 \mathrm{li}$ tros, foi usada para a embalagem dos frutos cortados ao meio. Os produtos foram armazenados a $3^{\circ} \mathrm{C}$, a $6^{\circ} \mathrm{C}$ e a $9^{\circ} \mathrm{C}$.

$\mathrm{O}$ rendimento em produtos minimamente processados foi determinado pela relação percentual entre o peso de produto processado e o peso do fruto inteiro, com coroa. Determinou-se a intensidade respiratória dos frutos inteiros, antes dos cortes, e a dos pedaços foi avaliada por até 26 horas após o preparo, mantendo-os em ambiente hermético por 01 hora e com determinações da quantidade de $\mathrm{CO}_{2}$, antes e após este tempo. A atmosfera interna na embalagem foi determinada diariamente e durante todo período de armazenamento. As determinações dos teores de $\mathrm{CO}_{2}$ foram feitas, utilizando-se cromatografia gasosa (Cromatógrafo Finnigan 9001). Determinaram-se também, diariamente, a perda de massa fresca, mediante pesagem, e a aparência, segundo a seguinte escala de notas: 1=bom (aparência "fresca" e coloração natural); 2 =regular ( sinais de murchamento e/ou ressecamento e início de amolecimento); e 3=ruim (murchamento e/ou ressecamento, escurecimento e amolecimento). A quantidade de suco drenado na embalagem, através da relação percentual entre o peso do produto e o peso do líquido drenado, e a presença de bactérias mesofílicas e coliformes, totais e fecais, foram avaliadas a cada 3 dias (APHA, 1992, ICMSF, 1978). Testaram-se também a textura, o sabor e a preferência pelos consumidores, em comparação ao produto fresco, no início e após 5 dias para os produtos armazenados a $9^{\circ} \mathrm{C}$ e após 7 dias, para os armazenados a $3^{\circ} \mathrm{C}$ e $6^{\circ} \mathrm{C}$ (Stevens e Albright, 1980). As amostras eram oferecidas a provadores não treinados, em quantidade suficiente para a prova, codificadas e em ambiente neutro. As avaliações eram feitas em escala não estruturada.

O delineamento estatístico foi o inteiramente casualizado, com esquema fatorial $2 \times 3$ ( 2 preparos e 3 temperaturas), com 6 tratamentos (épocas de amostragem) e 3 repetições, tendo como unidade experimental uma embalagem de produto (Gomes, 1982). A análise de variância e a comparação de médias foram feitas, utilizando-se do programa computacional ESTAT da FCAV/ UNESP. 


\section{RESULTADOS E DISCUSSÃO}

O rendimento dos abacaxis nos produtos minimamente processados foi de $61,84 \pm 1,07 \%$. As embalagens com os produtos em "rodelas" apresentavam massa de $558,31 \pm 10,98 \mathrm{~g}$ e as com "metades", $337,02+8,63 \mathrm{~g}$.

Durante o período de armazenamento, houve decréscimo no conteúdo de $\mathrm{O}_{2}$ nas embalagens que continham os frutos cortados em "metades", cuja variação foi de 18,03\% para 4,80\% em 12 dias, enquanto nas embalagens com as "rodelas", isto não aconteceu, e a variação foi de $18,23 \%$ a 18,04\% (dados não mostrados). Estes valores foram reflexo da associação entre o tipo de preparo e a embalagem, dada a menor permeabilidade da embalagem com o filme de PVC a trocas gasosas do que a de PET, a qual permite grandes trocas com o ambiente de armazenamento, devido ao seu fechamento não hermético.

Conforme o indicado por Wiley (1994), a concentração de $\mathrm{CO}_{2}$ dentro das embalagens aumentou com o período de armazenamento. Os maiores valores foram atingidos naquelas contendo as "metades" embaladas com PVC (20,0\% aos 12 dias), enquanto, nas contendo as "rodelas" embaladas em PET, os valores máximos foram de $1,11 \%$ e 1,86\%, aos 5 e 7 dias, respectivamente, com diminuição até o $12^{\circ}$ dia $(0,64 \%)$.

Verificou-se, também, efeito significativo das diferentes temperaturas, com os produtos a $9^{\circ} \mathrm{C}$ apresentando os maiores conteúdos médios de $\mathrm{CO}_{2}(12,26 \%)$, enquanto os armazenados a $3^{\circ} \mathrm{C}$ e $6^{\circ} \mathrm{C}$ apresentaram os menores valores $(5,77 \%$ e $9,72 \%$, respectivamente). Não houve interação entre os fatores preparo e temperatura de armazenamento para esta variável.

A Figura 1 apresenta o comportamento respiratório dos produtos minimamente processados do abacaxi-'Pérola', para os dois tipos de preparo e armazenados a $3^{\circ} \mathrm{C}, 6^{\circ} \mathrm{C}$ e $9^{\circ} \mathrm{C}$. O padrão respiratório foi semelhante em todos os tratamentos. Ocorreu um pico de evolução de $\mathrm{CO}_{2}$ na primeira hora após o preparo, seguido de redução e estabilização. Tal comportamento também foi observado por Rosen \& Kader (1989), em peras e morango. Chitarra (1999) afirmou que este aumento na atividade respiratória se inicia nos primeiros minutos após o preparo.

O abacaxi em "rodelas" apresentou maiores taxas respiratórias do que o cortado ao meio, independentemente da temperatura de armazenamento (Figura 1). Esta diferença pode ser atribuída à maior intensidade do estresse causado pelo preparo em "rodelas" (Tatsumi et al., 1991). Este efeito foi minimizado com o

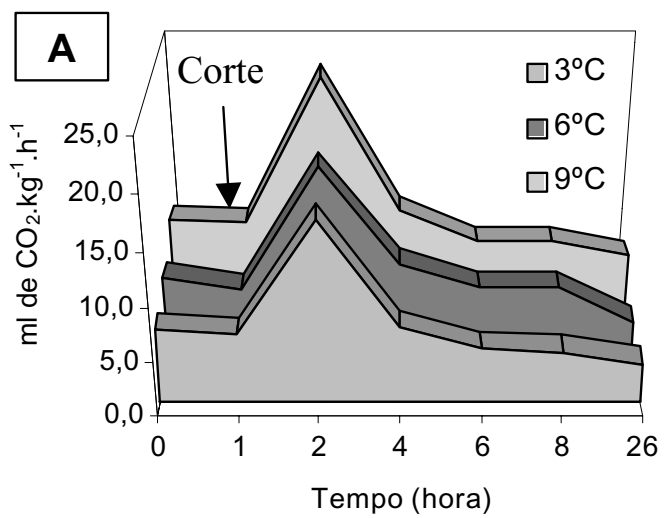

armazenamento sob temperaturas mais baixas, havendo uma diferença menor entre "rodelas" e "metades" para os produtos armazenados a $3^{\circ} \mathrm{C}$.

Os produtos armazenados a $3^{\circ} \mathrm{C}$ e $6^{\circ} \mathrm{C}$ mantiveram aparência adequada para a comercialização, indicada pela nota 2 , até o $9^{\circ}$ dia, enquanto os armazenados a $9^{\circ} \mathrm{C}$ a mantiveram por 6 dias, sendo descartados no $9^{\circ}$ dia (dados não mostrados). Prado et al. (2000) também observaram que o abacaxi-'Pérola', quando minimamente processado e armazenado a $8^{\circ} \mathrm{C}$, manteve aparência e sabor adequados ao consumo, por até 6 dias.

Fez-se também uma avaliação visual dos produtos quanto à preferência e à possibilidade de compra. No início, 92,3\% dos provadores mostraram sua preferência e opção de compra pelo abacaxi em "rodelas", mas esta porcentagem diminuiu para $60 \%$ após 7 dias (dados não mostrados).

A análise sensorial também permitiu verificar que a textura dos produtos não diferiu significativamente do cortado na hora ("fresco"), mesmo após armazenamento (Tabela 1). Não se observou diferença estatística entre os tratamentos, indicando que o processamento mínimo, independentemente da temperatura ou do tipo de preparo, não afetou esta variável. Os produtos mantiveram o sabor natural, indicado pela ausência de diferença significativa entre os tratamentos e destes com o produto "fresco", apesar de diminuição nos valores das notas recebidas. A preferência confirmou o observado para o sabor e, mesmo após armazenamento, os produtos não diferiram do produto "fresco", indicando que o mesmo se encontrava bom para o consumo. Os produtos armazenados a $3^{\circ} \mathrm{C}$ e a $6^{\circ} \mathrm{C}$ reuniram as melhores características além de apresentarem as maiores vidas de prateleira.

Os produtos perderam suco durante o período de armazenamento, e o tipo de preparo influenciou significativamente nesta perda, que foi menor no produto em "metades" (Tabela 2). A maior perda de líquido pelas "rodelas" pode ser atribuída à maior injúria sofrida no corte, já que, em produtos minimamente processados, quanto maior a intensidade dos cortes, maior será o rompimento de estruturas, facilitando a perda de líquido pelos tecidos, o que é aumentado com o tempo de armazenamento (Tatsumi et al., 1991). Temperaturas mais altas de armazenamento também levaram a maiores porcentagens de perda de líquido.

A perda de massa fresca, durante o período de armazenamento, pelo produto submetido aos diferentes tratamentos, foi sempre maior no cortado em "metades" (Figura 2A).

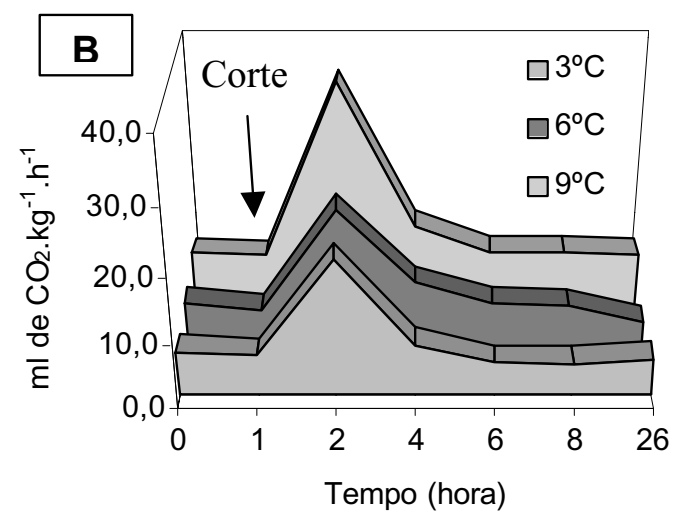

FIGURA 1 - Evolução de gás carbônico $\left(\mathrm{ml} \mathrm{CO}_{2} \cdot \mathrm{kg}^{-1} \cdot \mathrm{h}^{-1}\right)$ de "metades" (A) e "rodelas" (B) de abacaxi-‘Pérola', armazenadas a $3^{\circ} \mathrm{C}, 6^{\circ} \mathrm{C}$ e $9^{\circ} \mathrm{C}$. Jaboticabal-SP, 2001. 
TABELA 1 - Textura, sabor e preferência dos produtos minimamente processados de abacaxi-'Pérola', quando armazenados a $3^{\circ} \mathrm{C}, 6^{\circ} \mathrm{C}$ e $9^{\circ} \mathrm{C}$. Jaboticabal-SP, 2001.

\begin{tabular}{lcccccc}
\hline Tratamento & \multicolumn{2}{c}{ Textura } & \multicolumn{2}{c}{ Sabor } & \multicolumn{2}{c}{ Preferência } \\
\hline & Início & Armaz. & Início & Armaz. ${ }^{*}$ & Início $^{\text {Armaz. }}{ }^{*}$ \\
\hline "Fresco" & $5,26 \mathrm{a}$ & $6,15 \mathrm{a}$ & $7,93 \mathrm{a}$ & $6,78 \mathrm{a}$ & $7,65 \mathrm{ab}$ & $7,09 \mathrm{a}$ \\
$3^{\circ} \mathrm{C}$ & $5,56 \mathrm{a}$ & $5,39 \mathrm{a}$ & $5,85 \mathrm{~b}$ & $5,95 \mathrm{a}$ & $6,78 \mathrm{~b}$ & $6,04 \mathrm{a}$ \\
$6^{\circ} \mathrm{C}$ & $5,44 \mathrm{a}$ & $5,68 \mathrm{a}$ & $8,15 \mathrm{a}$ & $6,17 \mathrm{a}$ & $8,75 \mathrm{a}$ & $5,67 \mathrm{a}$ \\
$9^{\circ} \mathrm{C}$ & $4,74 \mathrm{a}$ & $5,15 \mathrm{a}$ & $6,51 \mathrm{~b}$ & $5,78 \mathrm{a}$ & $6,61 \mathrm{~b}$ & $6,34 \mathrm{a}$ \\
$\operatorname{cv}(\%)$ & 17,97 & 20,79 & 13,9 & 19,52 & 13,36 & 25,05 \\
\hline
\end{tabular}

Médias seguidas de mesma letra, na coluna, não diferem significativamente entre si, ao nível de $5 \%$ de probabilidade, pelo Teste de Tukey. ${ }^{*}$ Os produtos armazenados a $3^{\circ} \mathrm{C}$ e $6^{\circ} \mathrm{C}$ foram avaliados após 7 dias de armazenamento e os a $9^{\circ} \mathrm{C}$, após 5 dias.

TABELA 2 - Quantidade de líquido drenado (\%) das embalagens contendo os produtos minimamente processados de abacaxi"Pérola", armazenados a $3^{\circ} \mathrm{C}, 6^{\circ} \mathrm{C}$ e $9^{\circ} \mathrm{C}$. Jaboticabal-SP, 2001.

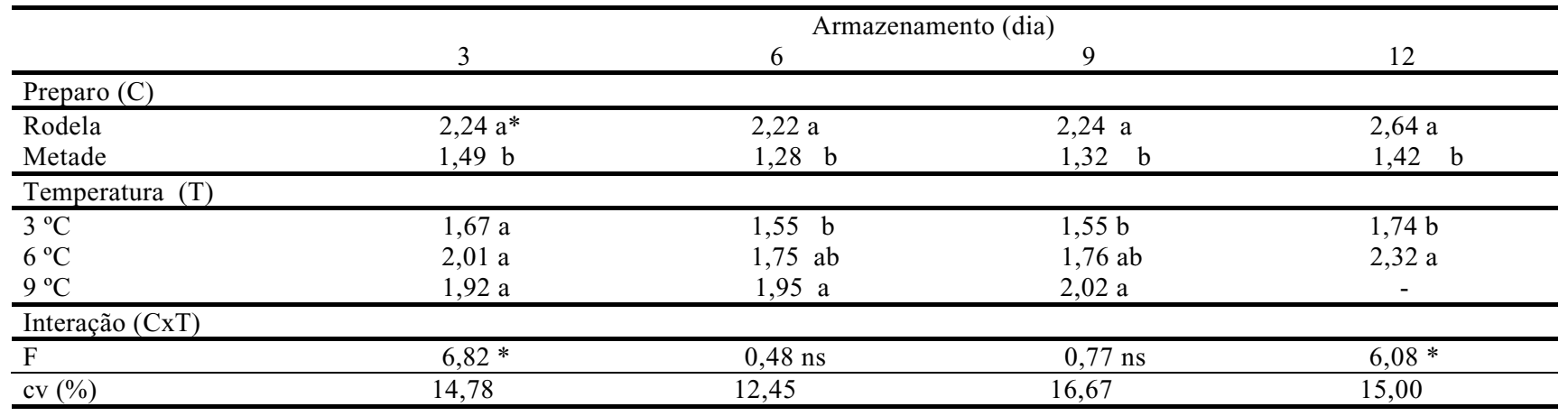

*Médias seguidas de mesma letra, na coluna, não diferem significativamente entre si, ao nível de $5 \%$ de probabilidade, pelo Teste de Tukey.

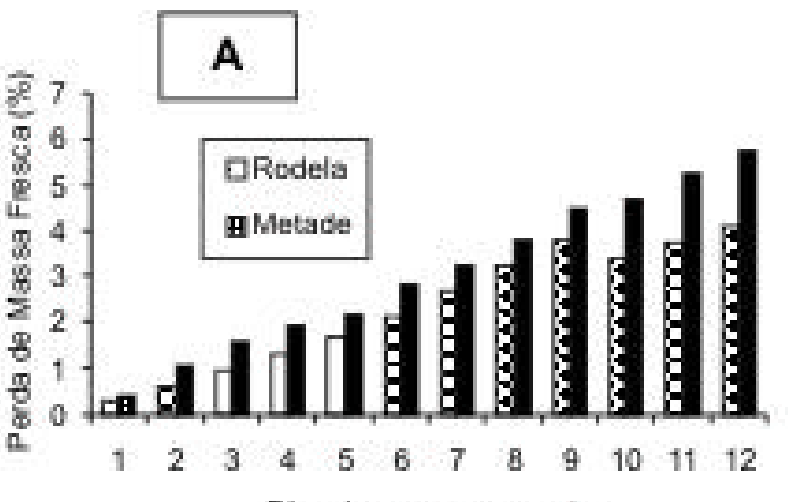

Diss de armazenamenta

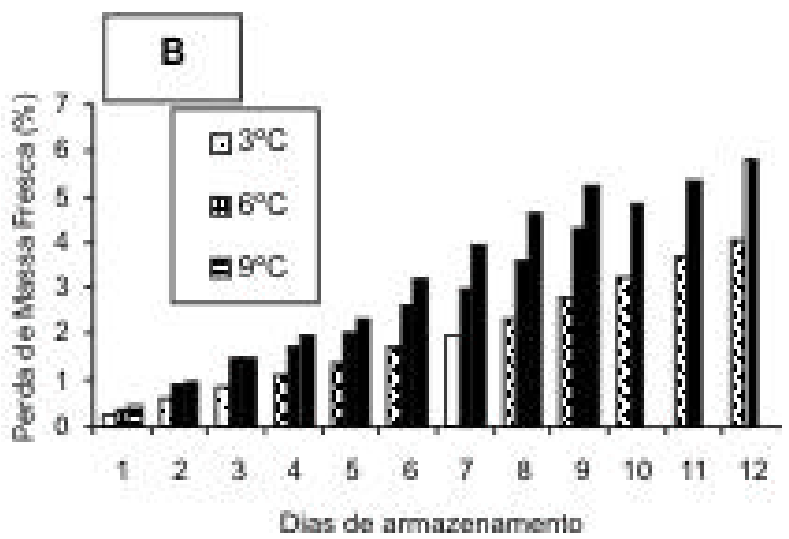

FIGURA 2 - Efeito do tipo de preparo (A) e da temperatura (B) na perda de massa fresca por produtos minimamente processados de abacaxi-'Pérola'. Jaboticabal-SP, 2001.

Apesar de as "rodelas" terem perdido mais líquido (Tabela 2), não se verificaram maiores perdas de massa fresca, pois este líquido ficou retido na embalagem. Os produtos armazenados a $9^{\circ} \mathrm{C}$ foram os que apresentaram as maiores perdas de massa fresca durante o armazenamento, enquanto, a $3^{\circ} \mathrm{C}$, os valores de perda foram sempre os menores (Figura 2B).

$\mathrm{O}$ controle das condições higiênicas, durante o processamento dos frutos, foi bastante eficiente, pois não se detectou a presença de coliformes totais ou fecais durante o armazenamento. A evolução da contagem de mesófilos foi muito pequena e, somente após 7 dias, os produtos armazenados a $9^{\circ} \mathrm{C}$ atingiram os valores de $10^{5} \mathrm{UFC} . \mathrm{g}^{-1}$, os quais são maiores que $\mathrm{o}$ valor $10^{3}$ UFC. $g^{-1}$ permitido pelo RDC $\mathrm{n}^{0} 12$ de 02-01-2000 publicada no Diário Oficial da União de 10-01-2000, o que levou ao descarte dos mesmos. Estes mesófilos não foram oriundos da contaminação pelo ambiente de preparo ou de armazenamento, 
uma vez que foi coincidente com a flora detectada em frutos "frescos". Os produtos armazenados a $3{ }^{\circ} \mathrm{C}$ ou a $6^{\circ} \mathrm{C}$ mantiveramse microbiologicamente adequados por até 13 dias após o processamento.

\section{CONCLUSÃO}

As "rodelas" e "metades" de abacaxi-'Pérola', quando embaladas em contentores de PET e PVC esticável, respectivamente, conservam boa aceitabilidade durante o armazenamento a $3^{\circ} \mathrm{C}, 6^{\circ} \mathrm{C}$ e $9^{\circ} \mathrm{C}$. Os produtos armazenados a $3^{\circ} \mathrm{C}$ e a $6^{\circ} \mathrm{C}$ apresentaram vida de prateleira mais longa ( 9 dias) em relação aos armazenados a $9^{\circ} \mathrm{C}$ (6 dias).

\section{REFERÊNCIAS BIBLIOGRÁFICAS}

AGRIANUAL 2001. Anuário da agricultura brasileira. São Paulo: FNP Consultoria e Comércio. 2001. p. 139-147.

AMERICAN PUBLIC HEALTH ASSOCIATION. Committee on Microbiological Methods for Foods. Compendium of methods for the microbiological examination of foods. 3.ed. Washington: American Public Health Association, 1992. 1219p.

CANTWELL, M. Postharvest handling systems: minimally processed fruits and vegetables. In: KADER, A. A. (Ed.) Postharvest technology of horticultural crops. Oakland: University of California, 1992. p.277-281.

CARBONARI, M.; SIGRIST, J. M. M.; SARANTOPOULOS, C. I. G. L.; FONSECA, E. S. Influência do corte e da embalagem em abacaxi minimamente processado. In: ENCONTRO NACIONAL SOBRE PROCESSAMENTO DE FRUTAS E HORTALIÇAS, 2 ., 2000, Viçosa. Resumos...Viçosa: Universidade Federal de Viçosa, 2000.p.3.

CHITARRA, M. I. F. Alterações bioquímicas do tecido vegetal com o processamento mínimo. In: SEMINÁRIO SOBRE HORTALIÇAS MINIMAMENTE PROCESSADAS, 1999, Piracicaba. Palestra... Piracicaba: ESALQ-USP, 1999.9p. Apostila.

CHITARRA, M. I. F.; CHITARRA, A. B. Pós-colheita de frutos e hortaliças: fisiologia e manuseio. Lavras: ESAL/Fundação de Apoio ao Ensino, Pesquisa e Extensão, 1990. 293p.
CLASSIFICAÇÃO do abacaxi (Ananas comosus (L.) Merril). Recife: Centro de qualidade em Horticultura CEAGESP, 2000. Fôlder.

DURIGAN, J. F. O processamento mínimo de frutas. In: CONGRESSO BRASILEIRO DE FRUTICULTURA, 16., 2000, Fortaleza. Palestra...Fortaleza: Sociedade Brasileira de Fruticultura, 2000. $12 \mathrm{p}$.

GOMES, F.P. Curso de estatística experimental. 10.ed. São Paulo: Nobel, 1982. 430p.

GONÇALVES, N.B.; CARVALHO, V.D. de. Características da fruta. In: GONÇALVES, N.B.(Org.). Abacaxi: pós-colheita. Brasília: Embrapa Comunicação para Transferência de Tecnologia, 2000. cap. 2, p.13-27 (Frutas do Brasil, 5).

INTERNATIONAL COMMITTEE ON MICROBIOLOGICAL SPECIFICATION FOR FOOD. Microorganisms in foods: I-Their significance and methods of enumeration. 2.ed. Toronto: University Press, 1978. 434p.

PRADO, M.E.T.; VILAS BOAS, E.V. de B.; SANTOS, J.C.B.; PINHEIRO, A.C.M.; MATTOS, L.M.; ARAÚJO, F.M.M.C.; CHITARRA, A.B.; OLIVEIRA, E.C M. Influência do hipoclorito de sódio sobre a qualidade de abacaxis minimamente processados. In: ENCONTRO NACIONAL SOBRE PROCESSAMENTO DE FRUTAS E HORTALIÇAS, 2., 2000, Viçosa. Resumos...Viçosa: Universidade Federal de Viçosa, 2000. p.5.

ROSEN, J.; KADER, A.A. Postharvest physiology and quality maintenance of sliced pear and strawberry fruits. Journal of Food Science, Chicago, v. 54, p.656-659, 1989.

STEVENS, M.A.; ALBRIGHT, M. An approach to sensory evaluation of horticultural commodities. HortScience, Alexandria, v. 15, n. 1, p. 48-50, 1980.

TATSUMI, Y.; WATADA, A.E.; WERGIN, W.P. Scanning electron microscopy of carrot stick surface to determine cause of white translucent appearance. Journal of Food Science, Chicago, v.56, p. 1357-1362, 1991.

WILEY, R. C. Minimally processed refrigerated fruits and vegetables. New York: Chapman \& Hall, 1994. 368p. 